\title{
Non-linear finite element analysis and limit analysis comparison of the Caaveiro stone arch bridge
}

\author{
J. Díaz, L. Romera \& S. Hernández \\ Department of Structural Engineering, University of La Coruña, Spain
}

\begin{abstract}
At the present time, there is no accepted procedure to determine the ultimate load that a masonry arch bridge can support. Unlike in the analysis of other structural typologies, it is not common to apply the finite element method to the structural analysis of this construction type. This is because it is rather complicated and expensive to know exactly many of the variables that characterize the structural behaviour of a model, such as material properties, load history, constructive sequence or its own geometric definition. On the other hand, the special configuration of masonry arches, with evident discontinuities in the joints between voussoirs, requires a unique and specific approach to the problem. It is not realistic to consider a totally homogenous structure, as occurs in other typologies and materials. In order to overcome these disadvantages, the purpose of this job is to develop a finite element model, which allows us to know with reasonable reliability, the maximum load that the bridge can support considering all the characteristics of the masonry structures, while keeping the computational cost under acceptable limits. The structure to be modelled is a stone arch bridge located next to the Caaveiro monastery in the northwest of Spain. The finite element model is a two-dimensional plane-stress model considering both geometric, material and contact nonlinearity. The results from this model are compared with those obtained from the limit analysis, considering the hypothesis of the plastic collapse of the structure.

Keywords: finite element, nonlinear analysis, limit analysis, arch bridge.
\end{abstract}




\section{Introduction}

Bridges form a very important part of our cultural heritage, and we still keep magnificent ones that we should preserve and maintain for our future generations. For this purpose, it is essential to learn and delimitate the loads that they can support without affecting its integrity since its carrying capacity has been diminished through the years.

In this job, the goal is obtain the ultimate failure load that the bridge of Caaveiro (figure 1), in the northwest of Spain, can support. In order to do that, two methodologies are applied: the limit analysis theory and the finite element method.

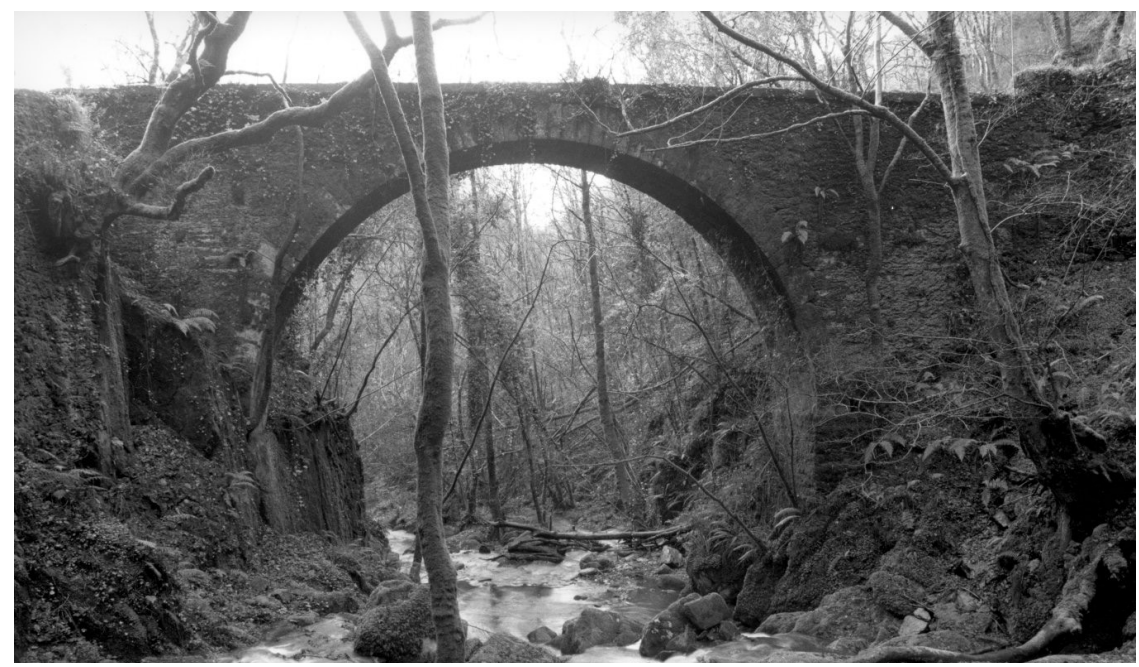

Figure 1: Elevation of the bridge of Caaveiro.

\section{Historical background}

The bridge is located in the old access trail to the Caaveiro monastery coming from As Neves. The path crosses O Pousadoiro going down a steep slope to look for a favourable place to cross the Sesin river. Because of very few documents available, determining the age of the bridge is very complicated. It needs to be done indirectly without specific historical testimony. According to Couceiro Freijomil [1], some events occurred as follows:

- The oldest document about the monastery is from year 930, when four monks were living in it.

- In 936, San Rosendo did an important donation to the monastery, when it started to gain importance. Many other donations followed, and in the 
XII century Don Alfonso and his wife, Doña Berenguela donated a great quantity of land to the monastery.

- The most active period of the monastery is found between the XII and XVI century and then it started to decline when Andrade family emerged to prosper. At the end of the XVIII century the last residents abandoned the monastery.

On the other hand, Ambrosio de Morales, a historian and traveller commissioned by Philip II to look for books and relics to provide to the El Escorial monastery says about Caaveiro [2]:

[...] It is very difficult to get there by foot and it is almost impossible by horse. That is why it stands in solitude.

Taking into account that the construction of the El Escorial monastery was finished at the end of the XVI, all the facts seem to indicate that the bridge did not exist at that time. They could have crossed the Sesin river by a more primitive bridge, or probably wading. It seems logical to associate the fate of the bridge with the one of the monastery since the bridge only existed for accessing to it. Ever since the foundation of Pontedeume in the XIII century, the road communications deviated toward the Eume estuary. Therefore it is not very probable that the bridge was constructed in the decline period of the monastery. If we count on the testimony of Ambrosio de Morales, since there is no more specific data available, the bridge construction was probably in the XVII century.

\section{Description of the bridge}

The bridge has a single round arch with 11.16 meter span length supported by two 2.73 and 2.23 meter height abutments (figure 2). The masonry is made of granite, a common rock in the region, with a constant thickness of $0.7 \mathrm{~m}$ and laid without mortar. There are 61 voussoirs of equal dimensions.

The spandrels are made of schist, well seated, but of lower quality than the one of the ashlars. The backfill is supposed to be a compact material, as no tests could be carried out. Because of the same reason, the mechanical properties have also been obtained from the literature [3] and are shown in table 1. The deck is horizontal and its width is $2.6 \mathrm{~m}$. It is formed by stone slabs and in the downstream side, there are remains of bridge parapet made of $0.7 \times 0.8 \times 0.25$ meter slabs for a distance of 14 meter long. There are also some small drainages in the vertical part of abutments to facilitate draining water of the deck.

Table 1: Material properties of the arch and backfill.

\begin{tabular}{lcccc}
\hline Element & $\gamma\left(\mathrm{kN} / \mathrm{m}^{3}\right)$ & $E(G P a)$ & $G(G P a)$ & $\nu$ \\
\hline Arch & 26.0 & 50.0 & 20.8 & 0.2 \\
Backfill & 20.0 & 0.1 & 0.04 & 0.3 \\
\hline
\end{tabular}




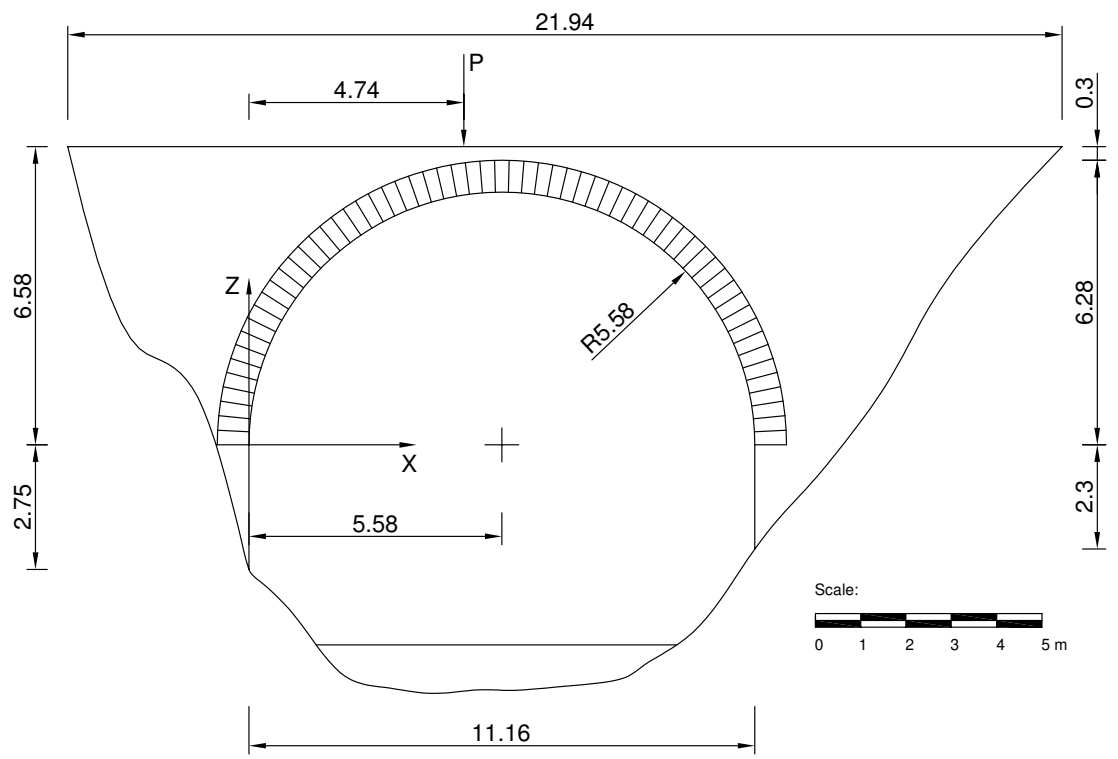

Figure 2: Dimensions of the bridge of Caaveiro.

\section{Ultimate load determination}

In order to determine the carrying capacity of the bridge, the limit analysis theory and the finite element method in linear and nonlinear theory were applied. The results and conclusions from those analyses are presented next.

\subsection{Limit analysis}

The application of the limit analysis to determine the carrying capacity of a stone bridge is based on the following hypothesis according to Heyman [4]:

- The structure is under compression and does not resist tensile forces.

- The blocks of stones, masonry and voussoirs that form the arch are made of an undeformable material and are sustained by their own weight.

- Since the compressive stresses are so low compared to the stone failure stress, a failure in compression is not considered.

- Friction between the blocks is sufficiently high so that they will not collapse sliding one on another.

Considering the previous hypothesis and the upper-bound theory of plasticity, four hinges are needed to form a kinematic admissible collapse mechanism in the case of this bridge. These hinges are formed when the thrust line is tangent to the arch parament. 
The dead loads considered were the self-weight of the voussoirs and the backfill load, although in this case, only the vertical component has been taken into account, to be on the safe side.

The live load was modelled as a concentrated load, and its worst case position was obtained by a parametric analysis whose results are shown in figure 3 . It is observed that the minimum collapse load occurs when the live load is situated at 4.74 meters from the coordinate origin. The effect of this load scatters in a uniform manner in the fill with a angle of $\pi / 6$ radians.

In order to perform the limit analysis, RING 1.5 software developed by Matthew Gilbert [5, 6] was used. The obtained results show that the collapse occurs when the live load is in the worst position with the critical collapse load of $210.94 \mathrm{KN}$ (figure 4).

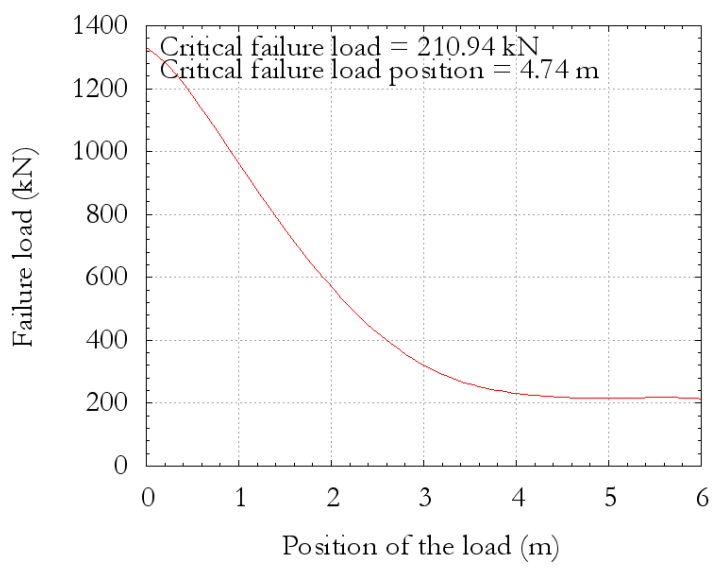

Figure 3: Failure load vs load position.

\subsection{Linear finite element analysis}

The models were developed with the Abaqus code 6.5 [7], including the arch and the abutments as a plane stress structure, with permanent boundary conditions applied in the bottom and lateral faces of the abutments and three loads applied sequentially: the self-weight of the arch, the backfill load applied as a vertical pressure on the extrados, and finally a concentrated load of $500 \mathrm{kN}$ applied as a vertical pressure in the position indicated in figure 2 over a length of $0.3 \mathrm{~m}$ in the extrados. In all models the constructive process has been taken into account, considering the geometrical non-linear behaviour and applying sequentially the three loads aforementioned. In the first stage with the self-weight load, all the arch intrados has null displacements as temporal boundary conditions that simulate the arch scaffolding. In the second stage these boundary restrictions are removed and 


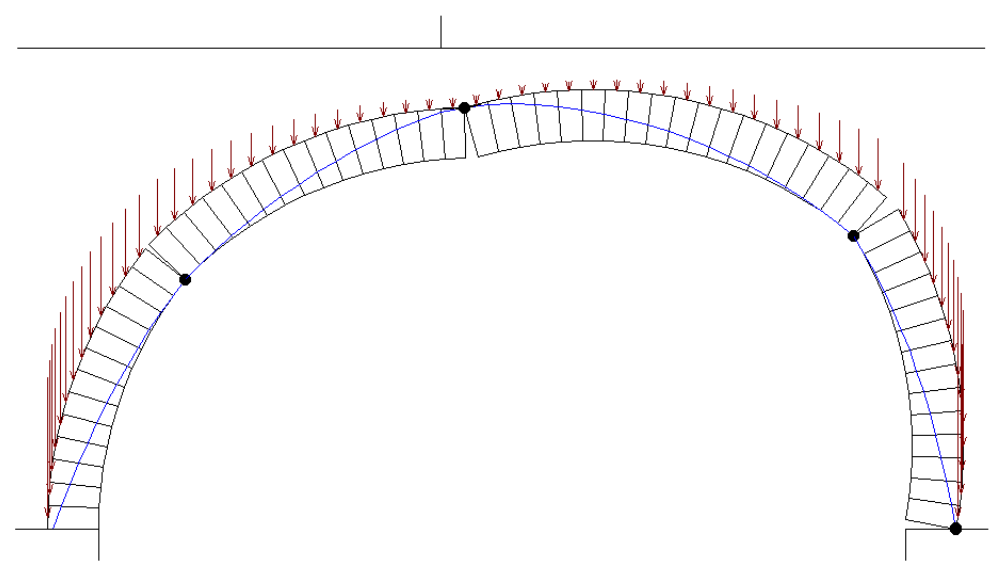

Figure 4: Critical collapse mechanism. Failure load 210.94 kN.

after that the backfill load is applied. Finally, in the third stage, the concentrated load is applied. The iterative procedure used in all cases was the Newton-Rapshon method in an implicit solver [8] with ten increments in each stage.

Considering an homogeneous linear elastic material for the voussoirs, with its properties shown in table 1, and a continuous model (figure 5), the results obtained in the last step with the three loads applied gives a maximum displacement of 0.857 $\mathrm{mm}$, a maximum principal tensile stress of $2776 \mathrm{kPa}$ and a maximum principal compressive stress of $4539 \mathrm{kPa}$. These results are in agreement with the behaviour of a reinforced concrete arch, but it is unrealistic for a stone arch. Compressive stresses are low compared with the expected stone compressive strength $\sigma_{c}=$ $15000 \mathrm{kPa}$, but tensile stresses are too high for the stone and the joints between voussoirs.

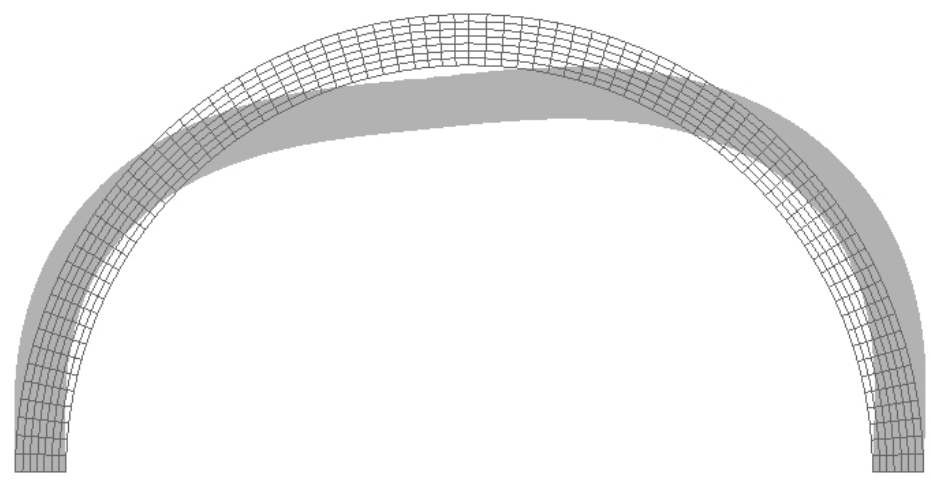

Figure 5: Finite element model and deformed shape (scale 1000). 


\subsection{Nonlinear finite element analysis}

In the next analysis, with the purpose of considering the possibility of opening in joints between voussoirs, a nonlinear material model with smear crack behaviour [9, 10] in tension and plasticity in compression (figure 6) was used with the following assumptions: a limit tensile cracking stress $\sigma_{c r}=0.1 \sigma_{c}$, an unloading module of elasticity of $10 \%$ of the linear value $E_{s}=0.1 E$, and a retention shear factor of 0.01 for open cracks. It is observed that the cracks begin under the concentrated load and at the connection with the right abutment (figure 7), with a distribution of tensile stresses in accordance with the limit analysis; but the obtained failure load has a very high value of $393 \mathrm{kN}$, obtained from the time increment in which the analysis does not converge in the three steps $(0.786 \times 500 \mathrm{kPa})$. The model is not able to simulate accurately the collapse mechanism.

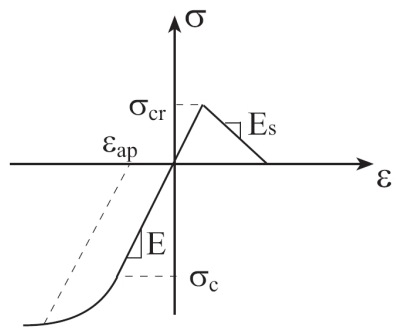
E Elastic modulus
$\mathrm{E}_{\mathrm{s}} \quad$ Discharge modulus
$\varepsilon_{\text {ap }}$ Crushing deformation
$\sigma_{\mathrm{cr}} \quad$ Cracking stress
$\sigma_{\mathrm{c}} \quad$ Yielding stress

Figure 6: Non-linear material model.

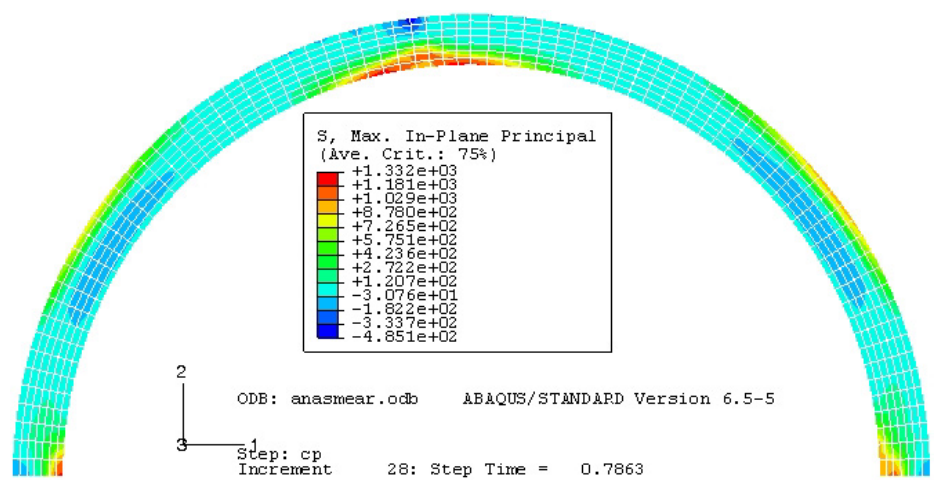

Figure 7: Maximum principal tensile stress with smear crack model (kPa).

In the last models, to simulate accurately the behaviour of joints between voussoirs, a general contact model was used. In a first stage, figure 8(a) shows one 
model with five contact lines and six independent blocks, four voussoirs and the abutments. Contact lines between voussoirs are coincident with the joint openings predicted by the limit analysis and each block has a mesh of plane stress element.

In order to have accordance with the limit analysis the contact type is hard (zero penetrations were allowed and instantaneous separation occurs with null pressure force if the gap is open) and rough (once the contact is established a null slip is allowed). The material model is linear, an hypothesis that was confirmed by the stress results obtained.

The obtained failure load with this model has a value of $224.5 \mathrm{kN}$ $(0.449 \times 500 \mathrm{kPa})$ close to the ultimate load of $210.94 \mathrm{kN}$ predicted by the limit analysis, and the geometry in the last converged increment previous to the collapse (figure 8(b)) also agrees. Maximum displacements are about $18.2 \mathrm{~mm}$ and the maximum principal tensile stress is a local value of $2698 \mathrm{kPa}$ in the connection between the arch and the right abutment. The maximum principal compressive stress reaches $10040 \mathrm{kPa}$ (figure 9).

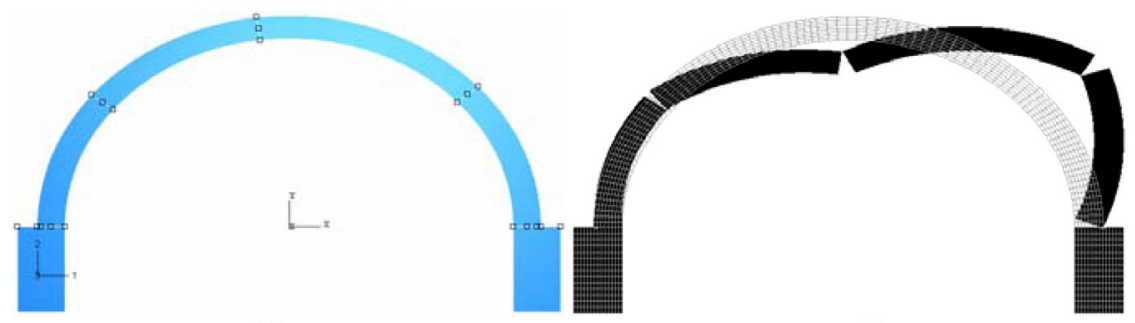

(a)

(b)

Figure 8: Model with contact lines (a) and deformed geometry in collapse scaled 100 times (b).

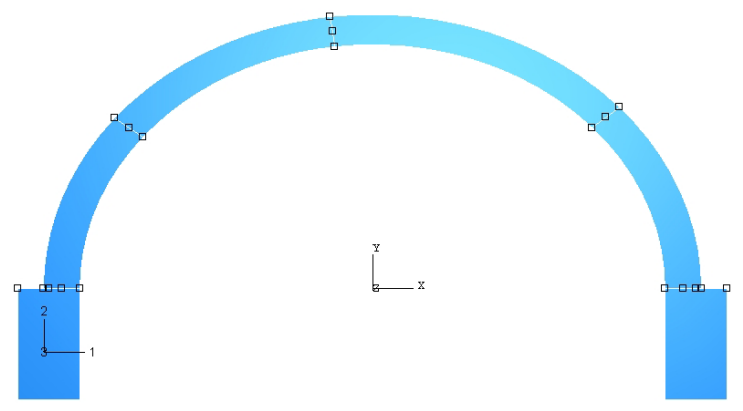

Figure 9: Maximum principal compressive stress with contact model (kPa). 
Finally, a more refined contact model was developed, considering each one of the voussoirs as an independent block with 64 contact lines (figure 10(a)). In this case, the hard contact model with rough friction does not converge when the scaffold is removed, and a new softened contact model for the normal behaviour with an exponential decay was used (figure 11) with $p_{o}=10 M P a$ and $a_{o}=0.1 \mathrm{~mm}$.

The obtained failure load with this model has a value of $275 \mathrm{kN}$ $(0.55 \times 500 \mathrm{kPa})$, greater than the obtained in the previous model due to the normal contact model used, and the geometry in the last converged increment previous to the collapse (figure 10(b)) also agrees. Maximum displacements are about $31.5 \mathrm{~mm}$, and the maximum and minimum principal stresses are similar to the ones obtained in the previous model and are shown in figures 12 and 13 . When the softened normal contact model is used with the same parameters applied to the simplified model with five independently blocks, a result of $198.6 \mathrm{kN}$ for the collapse load is obtained.

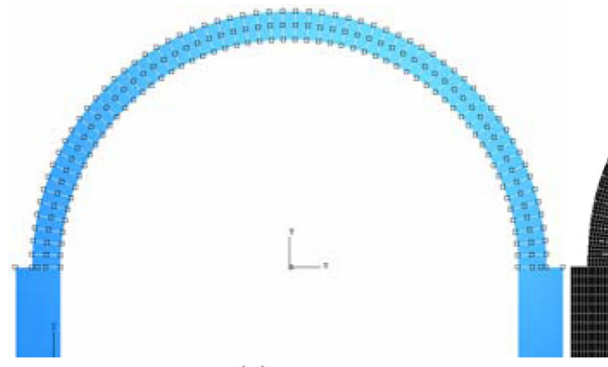

(a)

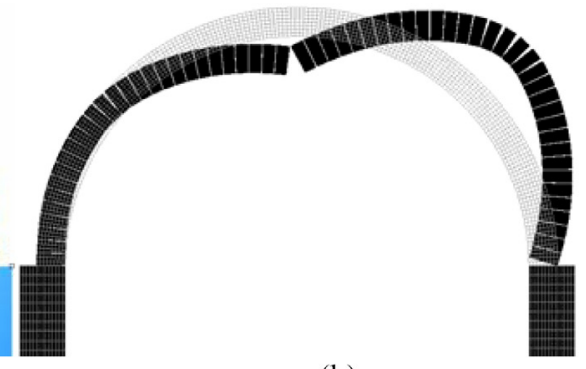

(b)

Figure 10: Model with contact lines (a) and deformed geometry in collapse scaled 50 times (b).

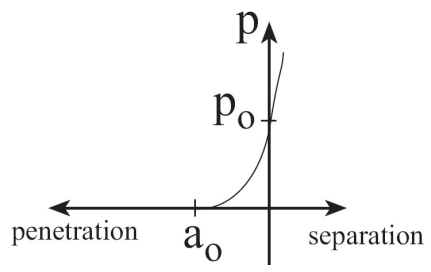

p Contact pressure

$\mathrm{p}_{\mathrm{o}} \quad$ Pressure for null gap

$\mathrm{a}_{\mathrm{o}} \quad$ Maximum penetration

Figure 11: Exponential softened contact model for the normal contact pressure. 


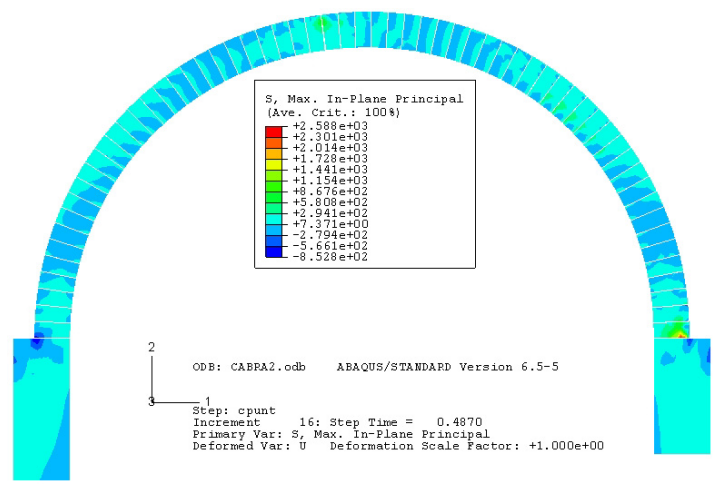

Figure 12: Maximum principal tensile stress (kPa).

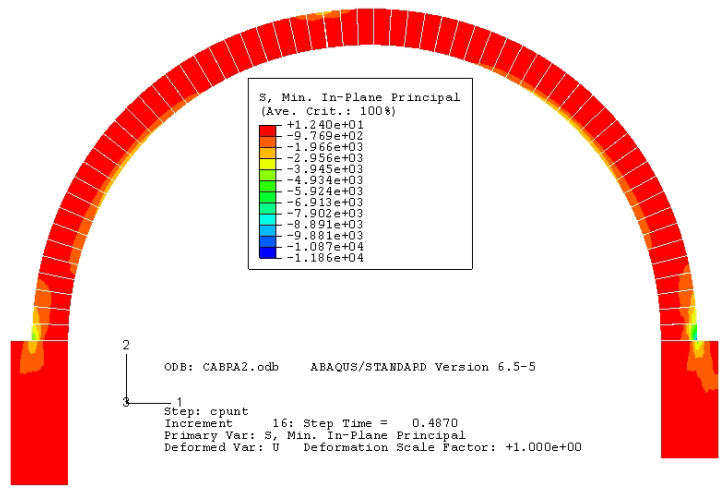

Figure 13: Maximum principal compressive stress (kPa).

\section{Conclusions}

From the analyses performed on the structure, the following conclusions are drawn:

1. The method of limit analysis is an efficient tool that provides the security level of a masonry arch rapidly without too many complications. In this case, its application is instant because of the simple bridge geometry, and there is no much difficulties using available calculation tools.

2. The finite element analysis is a widely used technique nowadays, however, in the case of historical masonry structures requires special attention to model the material behaviour. The main obstacle is to obtain the parameters that characterize its behaviour. It is common to consult upon a specific bibliography since characterization testings are usually expensive and difficult to interpret. 
3. The main advantage of the finite element method over the limit analysis is easiness for modelling complex geometries. In this case, as already mentioned, a semicircle is perfectly approachable using both techniques. However in other geometry the application of the limit analysis may not be so immediate, while the finite element model requires a little more time for modelling without major difficulties.

4. The nonlinear calculation methods provides us a more precise understanding of the structural behaviours, however, its application is much more complex than the linear methods requiring more time for modelling, calculation and interpretation. Nonlinear application to the stone materials is not too advanced as in the case of other types of material, and the current calculation programs do not simulate specific models for these cases. We need to look for specialized programs or use a programming technique to be implemented in the conventional calculation packages.

5. Results obtained from the finite element models with contact characterization of joints are in good accordance with the limit analysis and give an approximation about the displacements and stresses developed by the structure in the collapse. For the Caaveiro arch these displacements are very small, with a maximum obtained about $0.03 \mathrm{~m}$.

6. Considering hard contact and rough friction in the finite element models of Caaveiro arch, all the results obtained are in accordance with the limit analysis, being the load limit obtained by this method at lower level and therefore on the side of safe. Although finite element analysis includes the stone flexibility and the limit analysis does not. If softened contact models were used the previous affirmation is not true and the results depend on the roughness and hardness of the stone.

7. In finite element analysis, when the rough friction behaviour was changed by slip-non slip Coulomb models, for friction coefficients about 0.5-0.6, typical for these dry joints, the limit load and collapse mechanisms obtained are very similar to those presented. If friction coefficients diminish to 0.3 , collapse takes place when the scaffolding structure was retired.

\section{References}

[1] Couceiro Freijomil, A., Historia de Puentedeume y su comarca. Imp. Vda. Miguel López Torre: Pontedeume, 1971.

[2] Flórez, E., (ed.) Viaje a los Reinos de León, y Galicia, y Principado de Asturias (facsímil). Biblioteca Popular Asturiana: Oviedo, 1977.

[3] Carmichael, R.S., (ed.) Handbook of Physical Properties of Rocks, volume II. CRC Press: Boca Raton, Florida, 2000.

[4] Heyman, J., The Masonry Arch. Ellis Horwood: Chichester, 1982.

[5] Gilbert, M., RING. Program Reference Guide. The University of Sheffield: Sheffield, 2005.

[6] Gilbert, M., RING. Theory and Modelling Guide. The University of Sheffield: Sheffield, 2005. 
566 Structural Studies, Repairs and Maintenance of Heritage Architecture X

[7] ABAQUS, I., (ed.) ABAQUS 6.5. Standard Users Manual. Pawtucket, Rhode Island, 2004.

[8] Bathe, K.J., Finite element procedures. Prentice Hall: Englewood Cliffs, N.J., 1996.

[9] Crisfield, M.A., Non-Linear Finite Element Analysis of Solids and Structures. Vol. 1: Essentials, volume 1. John Wiley \& Sons: Chichester, 1998.

[10] Crisfield, M.A., Non-Linear Finite Element Analysis of Solids and Structures. Vol. 2: Advanced Topics, volume 2. John Wiley \& Sons: Chichester, 2001. 